\title{
Life Expectancy of White and Non-White Elite Heavyweight Boxers
}

\author{
Thang S. Han ${ }^{1,2}$ (D) Jonathan Gabe ${ }^{3} \cdot$ Pankaj Sharma ${ }^{1,4} \cdot$ Michael E. J. Lean $^{5}$
}

Received: 22 July 2019 / Revised: 14 October 2019 / Accepted: 14 October 2019/Published online: 3 December 2019

(C) The Author(s) 2019

\begin{abstract}
Background In post-industrial countries, ethnic minorities suffer poorer health and premature deaths. The present study examined ethnic differences in life expectancy and related features among elite heavyweight boxers.

Methods Dates of birth and death, anthropometry, and championship years were gathered from media archives for champions and challengers (never been a champion) between years 1889 and 2019. Cox regression adjusted for age at contest, nationality, BMI, champion/challenger status, and number of contests was used to assess survival.

Results All 237 boxers, 83 champions (37.3\% whites) and 154 challengers (61.0\% whites), who contested for heavyweight championships were identified. By 2019, 110 (75 whites, 34 non-whites) were known to have died. Non-white boxers died at an earlier age than whites boxers (mean $\pm \mathrm{SD}=59.8 \pm 14.2$ years versus $67.3 \pm 16.4$ years, $p=0.018$ ) and had shorter survival: $\mathrm{HR}=$ 2.13 (95\% CI = 1.4-3.3). Among non-white boxers, deaths were higher from neurological disorders: $\mathrm{OR}=8.2(95 \% \mathrm{CI}=1.3-$ $13.5)$ and accidents: $\mathrm{OR}=15.1(95 \% \mathrm{CI}=2.3-98.2)$, while death from natural causes was lower: $\mathrm{OR}=0.2(95 \% \mathrm{CI}=0.03-0.8)$. After boxing careers, fewer non-white boxers had non-manual jobs (34.4\% versus $71.8 \%)$ than manual (34.4\% versus $19.7 \%)$ or were unemployed $(28.1 \%$ versus $2.8 \%)$. Reported substance abuse was similar across ethnicity $(8.0 \%$ versus $8.8 \%)$ but conviction rates were higher among non-white boxers $(17.6 \%)$ than white $(1.3 \%)$.

Conclusions Compared with white boxers, non-white boxers tend to die younger with excess neurological and accidental deaths, and they have lower social positions in later life. Sporting authorities should reappraise the wisdom of permitting head injuries in sport and monitor and support the health and wellbeing of sports men and women after retirement.
\end{abstract}

Keywords Premature death $\cdot$ Social mobility $\cdot$ Ethnic minorities $\cdot$ Employment $\cdot$ Chronic traumatic encephalopathy

\begin{abstract}
Key points
- In most post-industrial countries, ethnic minorities suffer poorer health and premature deaths. These disparities may also exist among elite heavyweight boxers.

- We show that compared with white boxers, non-white boxers had shorter survival and higher rates of death from neurological disorders and from accidents. After their boxing careers had ended, fewer nonwhite boxers had non-manual jobs than manual jobs and were more likely to be unemployed. Reported substance abuse was similar across ethnic groups but conviction rates were higher among non-white boxers.

- Sporting authorities should reappraise the wisdom of permitting head injuries in sport and monitor and support the health and wellbeing of sportsmen and women after retirement.
\end{abstract}

Thang S. Han

thang.han@rhul.ac.uk

1 Institute of Cardiovascular Research, Royal Holloway, University of London, Egham TW10 0EX, UK

2 Department of Endocrinology, Ashford \& St Peter's NHS Foundation Trust, Surrey, UK
3 Department of Criminology and Sociology, School of Law, Royal Holloway, University of London, Egham, UK

4 Department of Clinical Neuroscience, Imperial College Healthcare NHS Trust, London, UK

5 Human Nutrition, School of Medicine, University of Glasgow, Glasgow, UK 


\section{Introduction}

In most post-industrial countries, members of ethnic minority groups experience a socioeconomic disadvantage $[1,2]$ which is associated with reduced access to health care, exposure to adverse environments, and consequently poorer health and early death [3-7]. This inequality not only occurs in developed countries but has also been observed in middle-income countries [8, 9]. Education is one route away from poverty while professional sport offers a more rapid alternative $[10,11]$. However, professional sports men and women have a short career span and many find transition to a new post-sport occupation challenging [12]. Studies of professional sportsmen at the end of their career have shown that sporting success does not necessarily provide a passage to better occupational opportunities [13]. Indeed, a study of a group of British professional football players has indicated that the majority of these players experienced downward mobility in terms of occupational status and income [14].

Studies have shown that those who are attracted to boxing often come from inner cities and single-parent households, and have limited formal education $[15,16]$. Blacks have been disproportionately drawn to boxing for a number of reasons: historically, boxing has been a relatively egalitarian sport where members of different ethnic groups can participate on a fairly equal level; it requires relatively limited facilities and equipment and consequently there tends to be a higher density of boxing clubs in minority neighbourhoods [17]; often, the lack other social opportunities makes boxing attractive to young men from minority groups [18, 19]. Floud et al. [20] argued that professional boxers have tended to come from socially deprived backgrounds where those who grow tallest commonly have better life-opportunities and thus experience upward social mobility. Choosing to become a boxer seems to offer a route to the rapid acquisition of substantial wealth and status $[15,21]$. Although there is a body of evidence on racial disparity in mental and physical health, life expectancy [22-24], and mortality [25] among the general population, no previous comprehensive study has assessed how ethnicity could influence the health and life expectancy of these elite boxers once their sporting career is over.

We sought to determine whether there exist ethnic differences in life-course after retirement from boxing, including (1) life expectancy, (2) cause of death, (3) occupation, and (4) substance abuse and convictions in white and non-white male heavyweight boxers who have contested for World Championship titles from 1889 to 2019.

\section{Methods}

\section{Data Procurement}

Data were collected from published media [26], primarily newspapers [27, 28], and supplemented by information from sports magazines, official fight programmes, books, encyclopaedias [29, 30], and publicly monitored websites [31] of all internationally recognised Heavyweight World boxing championships from the first ever official contest (8 August 1889) to the most recent contest ( 8 February 2019). The present study did not involve patients or the public directly.

\section{Demographic and Anthropometric Data}

Demographic information of male boxers recorded at the time of the championship contests was collected, including date of birth and date of death, cause of death, occupation after boxing career, substance abuse and convictions, champion/ challenger status (champions of any of the recognised World boxing titles, principally World Boxing Council, World Boxing Association, World Boxing Organization and International Boxing Federation [32], and unsuccessful challengers who contested but never prevailed in any of the World title bouts), nationality (categorised as North America, Europe, and others), and ethnicity (American white; AfricanAmerican; European white; and others including mixed race, Hispanic, Samoan, and African) [33]. Weight and height were also collected and BMI calculated as weight/height squared.

\section{Categorisation of Outcome Measures}

Ethnicity was grouped into whites and non-whites; nationality into North America, Europe, and others; and occupation into non-manual, manual, and unemployed. Causes of death include neurological disorders (dementia, stroke), accidents (involving aeroplane, automobile and road traffic, and work accidents), cancers of any aetiology, homicides (murder by any method), metabolic disorders (diabetes, liver and kidney failure), infections (pneumonia, sepsis), cardiac conditions (coronary heart disease, heart failure), and natural causes (due to old age). Reported occupations (day jobs) were classified into nonmanual jobs (successful business, managers, public officials, shop ownership, established acting career), manual jobs (doorman, truck driving, training boxers), and unemployed (no day job). Five boxers who died during their boxing career were not included in the analysis in relation to occupational status. Substance abuse includes those who have been reported to have a problem with alcoholism and use of illicit drugs, and convictions include illegal activities that resulted in imprisonment.

\section{Statistical Analysis}

Chi-squared tests were performed to assess differences in the proportion of deaths in different categories of age of death or cause of death between ethnic groups. Cox regression and Kaplan-Meier survival curves were performed to examine the risk of early death and logistic regression causes of death in white (referent group) and non-white boxers. Data were 
adjusted for age at contest, nationality, champion/challenger status, BMI, and number of boxing matches (or rounds). Analyses were conducted using IBM SPSS Statistics for Windows, version 23.0 (IBM Corp., Armonk, NY, USA). The null hypothesis was rejected when $p<0.05$.

\section{Results}

\section{Demographic Features}

All 239 boxers who contested heavyweight championships of the World between 1889 and 2019 were identified. Two who were stripped of the titles after being found positive for the use of banned substances were excluded, leaving 237 for analysis. $35.0 \%$ were champions and $65.0 \%$ were unsuccessful challengers. $65.0 \%$ of all boxers came from North America, $18.3 \%$ from European countries, and $10.5 \%$ from elsewhere. Of these boxers, $52.7 \%$ were white and $47.3 \%$ non-white. $10.5 \%$ of boxers were known to have a history of substance abuse or convictions, $59.6 \%$ had non-manual jobs, and $24.0 \%$ manual jobs, while $10.6 \%$ were unemployed. Neurological disorders $(15.5 \%)$ and cardiac conditions were among the highest causes of death $(16.4 \%)$.

The mean $( \pm \mathrm{SD}) \mathrm{BMI}$ was $\left.27.8 \pm 2.4 \mathrm{~kg} / \mathrm{m}^{2}\right)$, and mean age at first championship contest was $28.9 \pm 4.1$ years and at last championship contest was $30.8 \pm 4.8$ years: mean difference of 1.8 years $(95 \% \mathrm{CI}=1.4-2.3)$. Among the 211 retired boxers, the median number of boxing matches contested was 53 (IQR $=41-66)$; there were no ethnic differences $(p=$ 0.639 ): 53 matches by whites and 52.5 matches by nonwhites. Similarly, the median number of rounds contested was $318(\mathrm{IQR}=215-442): 332$ rounds by whites and 313 rounds by non-whites $(p=0.272)$. The proportions of those competing for heavyweight titles for the first championship contest at the age of 30-35 years were $24.9 \%,>35-40$ years were $5.9 \%$, and $>40$ years were $1.7 \%$, and the corresponding proportions for the last championship contest were 50.2\%, $32.5 \%, 13.5 \%$, and $3.8 \%$, respectively. The duration of reign as a champion was usually brief, with a median reign of 1.0 year (IQR $=0.6-2.0)$; only $6 \%$ of champion boxers reigned over 4 years. The majority of champions $(67.5 \%)$ never competed again at the highest level of heavyweight boxing.

\section{Comparison of Life Expectancy Between Ethnic Groups}

By 2019, 110 boxers (75 whites, 34 non-whites) were known to have died (1 white boxer with unknown date of death). Non-white boxers died at an earlier age than whites boxers (mean $\pm \mathrm{SD}=59.8 \pm 14.2$ years versus $67.3 \pm 16.4$ years, $p=$ 0.018). In comparison with published data for the general US population, the average life expectancy of white males was
75.7 years and black males was 69.5 years in 2006, and rose to 76.1 years for whites and 71.5 years for blacks a decade later in 2017 [34]. Compared with their respective racial groups in the general US population, non-white boxers had 9.7 years shorter life expectancy and white boxers had 8.4 years shorter life expectancy in 2006, while non-white boxers had 11.7 years shorter life expectancy and white boxers had 8.8 years shorter life expectancy in 2017.

Kaplan-Meier survival plot (Fig. 1) shows that compared with white boxers, non-white boxers had a significantly shorter survival: Log rank (Cox-Mantel) test: $\chi^{2}=10.3, p=0.001$, and adjusted hazard ratio $=2.13(95 \% \mathrm{CI}=1.38-3.28)$. Shorter survival was also observed in those with a history of substance abuse: adjusted hazard ratio $=2.28(95 \% \mathrm{CI}=1.27-4.10)$ or with high BMI: adjusted hazard ratio $=2.46(95 \% \mathrm{CI}=1.12-5.42)$ (Table 1).

\section{Comparison of Causes of Death Between Ethnic Groups}

Among the 75 white and 34 non-white boxers who had died, the cause of death was mentioned in obituaries for $72(96 \%)$ white and $31(91.2 \%)$ non-white boxers. The proportions of leading causes of death are shown in Fig. 2. There were significant ethnic differences in four of these leading causes of death; compared with white boxers, non-white boxers had significantly higher proportions of deaths from neurological disorders $(10.7 \%$ versus $26.5 \%, p=0.037)$ and accidents (2.7\% versus $20.6 \%, p=0.004)$, and lower proportions of deaths from cardiac disease $(21.3$ versus $5.9 \%, p=0.035)$ and natural causes (32.0 versus $5.9 \%, p=0.002$ ). There were no differences for the remaining causes of death (cancer, homicide, metabolic, and infections). Table 2 shows that

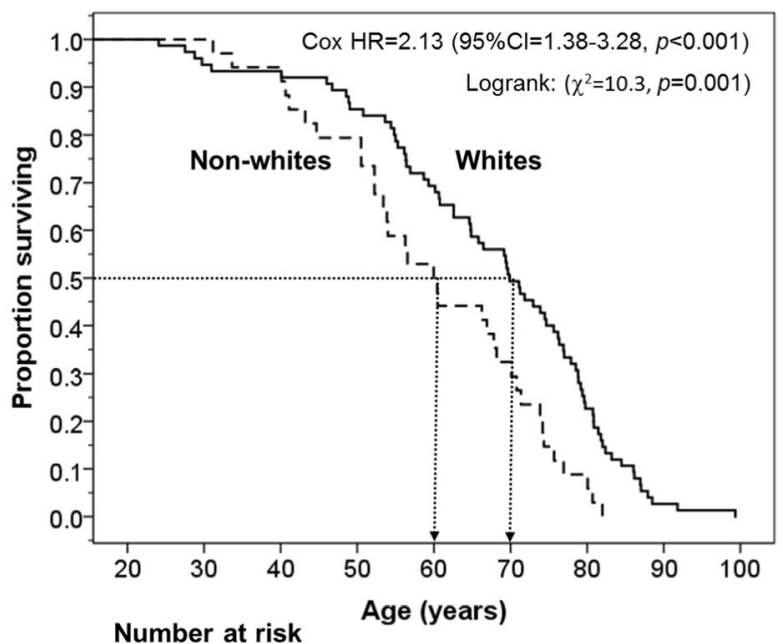

$\begin{array}{llllllllll}\text { Whites: } & 75 & 71 & 70 & 64 & 52 & 37 & 17 & 2 & 0\end{array}$ Non-whites: $\begin{array}{lllllll}34 & 32 & 27 & 17 & 11 & 3 & 0\end{array}$

Fig. 1 Kaplan-Meier survival plot in 75 white (solid line) and 34 nonwhite (dashed line) boxers. The dotted lines delineates the median age of the two ethnic groups 
Table 1 Stepwise multivariable Cox proportional hazards regression to assess factors associated with increased hazard of short survival in elite heavyweight boxers. All variables were entered simultaneously as covariates to adjust for each other

\begin{tabular}{llll}
\hline & \multicolumn{2}{l}{ Stepwise Cox regression analysis } \\
\cline { 2 - 4 } Variables retained by stepwise procedure & Hazard ratio & $95 \%$ confidence interval & $p$ \\
\hline Ethnicity & 1 & & - \\
White boxers (reference) & 2.13 & - & - \\
Non-white boxers & & $1.38-3.28$ & 0.001 \\
Substance abuse & 1 & - & - \\
No reported substance abuse (reference) & 2.28 & $1.27-4.10$ & 0.006 \\
Reported substance abuse & & & - \\
Adiposity & 1 & - & 0.025 \\
BMI $<30 \mathrm{~kg} / \mathrm{m}^{2}$ (reference) & 2.46 & $1.12-5.42$ & \\
BMI $\geq 30 \mathrm{~kg} / \mathrm{m}^{2}$ & & & \\
\hline
\end{tabular}

Variables eliminated from stepwise procedure: Champion/challenger status, regions, reported convictions, age at contest, boxing career span (or age of retirement of boxing), and number of boxing matches; Italicized values indicate significant association between variables compared with white boxers, non-white boxers had a higher risk of death from neurological disorders: adjusted odds ratios $=4.18(95 \% \mathrm{CI}=1.29-13.51)$ and death from accidents: adjusted odds ratio $=15.11(95 \% \mathrm{CI}=2.33-98.20)$, while the risk of death from cardiac disorders was lower: adjusted odds ratio $=0.11(95 \% \mathrm{CI}=0.01-0.79)$ and from natural causes: adjusted odds ratio $=0.16(95 \% \mathrm{CI}=0.03-0.75)$.

\section{Comparison of Post-Boxing Careers Between Ethnic Groups}

Occupations after the end of boxing career were available for analysis from news archives for 104 deceased boxers (71 white, 33 non-white). Overall, $60.2 \%$ of them had had nonmanual jobs; $24.3 \%$ manual jobs, with $10.7 \%$ reported as unemployed; and $4.9 \%$ as not known. Among white boxers, $71.8 \%$ had non-manual jobs, $19.7 \%$ had manual jobs, and $2.8 \%$ were unemployed or involved in illegal trades. In

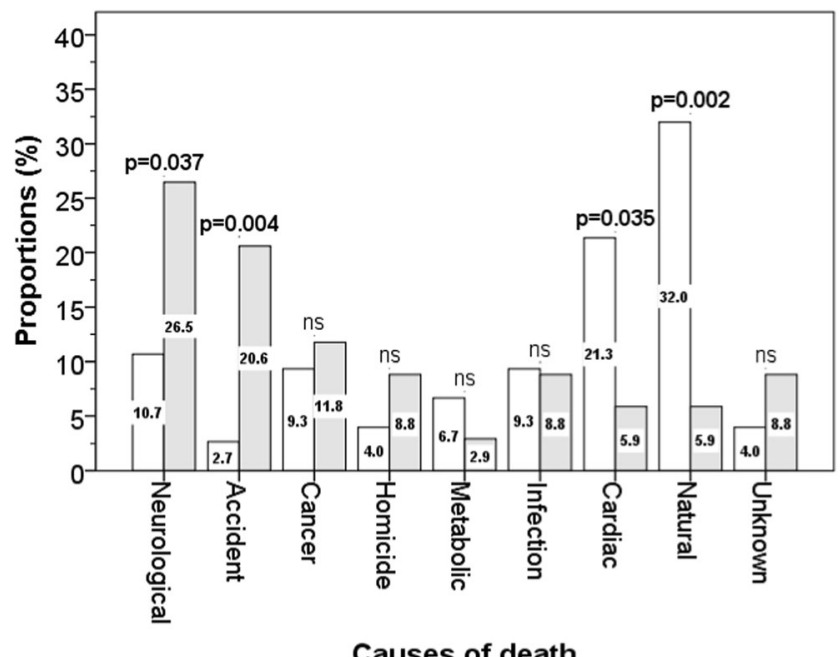

Fig. 2 Causes of death in white (open bars) and non-white boxers (grey bars) comparison, among non-white boxers only, $34.4 \%$ had nonmanual jobs and $34.4 \%$ had manual jobs, while $28.1 \%$ were unemployed or involved in illegal trades (Fig. 3a; Table 2).

Among those who died in the lowest tertile of age of death, $43.3 \%$ had non-manual jobs, $23.3 \%$ had manual jobs, and $30.0 \%$ were unemployed. In contrast, among those who lived longest (in the highest tertile of age of death), $69.4 \%$ had nonmanual jobs, $22.2 \%$ had manual jobs, and none were reported as being unemployed (Fig. 3b).

\section{Comparison of Substance Abuse and Convictions Between Ethnic Groups}

Based on news archives, a total of 9 boxers $(8.3 \%)$ were reported to have problems with substance abuse and 7 (6.4\%) had a criminal conviction. The proportions of those with substance abuse were similar in white and non-white boxers ( $8.0 \%$ versus $8.8 \%$ ) but non-white boxers had higher proportions of conviction, $17.6 \%$ versus $1.3 \%$ (Fig. 4a). Substance abuse was highest among the non-manual group (55.6\%) and unemployed boxers (33.3\%). Convictions were not reported in the non-manual group, but two convictions were reported in the manual group $(8.0 \%)$ and five convictions were reported among the unemployed (45.5\%) (Fig. 4b).

\section{Discussion}

\section{Summary}

The present study found that among elite heavyweight boxers, non-white boxers died at earlier ages and were more likely to have died from neurological disorders and accidents. Nonwhite boxers also had higher rates of manual jobs or unemployment and a greater frequency of reported criminal 
Table 2 Risk of death from different causes in non-white boxers compared with white boxers

\begin{tabular}{|c|c|c|c|c|c|c|c|c|c|c|}
\hline & \multicolumn{4}{|c|}{ Event rates } & \multicolumn{3}{|c|}{ Unadjusted } & \multicolumn{3}{|c|}{$\begin{array}{l}\text { Adjusted for age at contest, substance abuse, } \\
\text { conviction, duration of boxing career span, } \\
\text { BMI, and number of boxing matches }{ }^{\dagger}\end{array}$} \\
\hline & $n$ & $\%$ & $\chi^{2}$ & $p$ & OR & $95 \% \mathrm{CI}$ & $p$ & OR & $95 \% \mathrm{CI}$ & $p$ \\
\hline \multicolumn{11}{|c|}{ Died from neurological disorders } \\
\hline White boxers (reference) & $8 / 75$ & 10.7 & 4.4 & 0.037 & 1 & -- & - & 1 & -- & -- \\
\hline Non-white boxers & $9 / 34$ & 26.5 & & & 3.06 & $1.06-8.81$ & 0.038 & 4.18 & $1.29-13.51$ & 0.017 \\
\hline \multicolumn{11}{|l|}{ Died from accidents } \\
\hline White boxers (reference) & $2 / 75$ & 2.7 & 9.9 & 0.004 & 1 & - & - & 1 & -- & -- \\
\hline Non-white boxers & $7 / 34$ & 20.6 & & & 9.95 & $1.88-49.06$ & 0.007 & 15.11 & $2.33-98.20$ & 0.004 \\
\hline \multicolumn{11}{|l|}{ Died from cardiac disorders } \\
\hline White boxers (reference) & $16 / 75$ & 21.3 & 4.1 & 0.035 & 1 & - & - & 1 & - & - \\
\hline Non-white boxers & $2 / 34$ & 5.9 & & & 0.23 & $0.05-1.08$ & 0.063 & 0.11 & $0.01-0.79$ & 0.029 \\
\hline \multicolumn{11}{|l|}{ Died from natural causes } \\
\hline White boxers (reference) & $24 / 75$ & 32.0 & 8.8 & 0.002 & 1 & - & - & 1 & -- & -- \\
\hline Non-white boxers & $2 / 34$ & 5.9 & & & 0.13 & $0.03-0.58$ & 0.007 & 0.16 & $0.03-0.75$ & 0.021 \\
\hline
\end{tabular}

${ }^{a}$ Adjustment for age at retirement from boxing instead of duration of boxing career span did not change the outcomes; Italicized values indicate significant association between variables

convictions. These findings indicate that despite championship wealth and status, ethnic differences still negatively affected social position and health for non-white boxers once their boxing careers are over. Our findings of ethnic differences in athletes mirror well known disparities in the general populations of the UK [35] and the USA [36].

\section{Health Consequences of Boxing}

Our study has shown that, on average, an elite heavyweight boxer contested 53 matches (318 rounds) during his boxing career (no ethnic differences). Boxing is the only sport that involves intentional repetitive pounding of the head often resulting in concussions and serious brain injuries including chronic traumatic encephalopathy (CTE), also known as dementia pugilistica manifesting as motor, cognitive, and behavioural impairments $[37,38]$. CTE has been shown to be associated with atrophy of the thalamus, hippocampi, and caudate [38-40]. Roberts et al. [41] performed a histological examination of the temporal lobe of boxers with CTE and found extensive $\beta$-protein plaque deposition in all cases which was comparable to the level observed in Alzheimer's disease. It is thought that head injury causing axonal, microvascular damage and inflammation may precipitate the neurodegenerative process of CTE [41, 42]. Impaired mental health, a feature of CTE, and involvement with drugs and alcoholism, and the law are also prevalent among boxers. While an excessive number of former boxers suffer from CTE and socioeconomic hardship, assistance from boxing governing bodies does not appear to exist. For example, the British Boxing Board of
Control only provides website links for mental health charities such as "Mind" for boxers with depression (www.bbbofc. com/content/rules-boxing-0).

The most striking observations specific to boxers were the increased risk of death from neurological disorders and accidents. These have been shown to exist among ethnic groups in general [43], but the risk appears to be exaggerated for boxers. Studies of patients admitted to hospital with traumatic brain injury has shown that compared with white patients, blacks and Hispanics have a higher mortality [44] and are more likely to be cared for by a junior doctor (resident) on acute admissions [45]. Other studies have found that non-whites were less likely to be insured and therefore less likely to be able to afford rehabilitation $[46,47]$. On the other hand, one study has revealed that even having the same insurance coverage (Medicare), blacks and Hispanics were less likely than whites to be transferred to facilities to receive a higher level of rehabilitation [48]. These health care inequalities could therefore explain the higher risk of death from neurological causes among non-white boxers observed in our study.

Cardiovascular disease is more prevalent among white boxers. Its later emergence may reflect their longevity, but their relatively high prevalence may also be related to their underlying body composition and muscle characteristics that enable them to perform this power sport. There is other evidence that people who excel in power sports (as opposed to endurance sports) have increased risk of cardiovascular disease in later life, possibly related to their greater proportion of glycolytic 'fast-twitch' type 2B muscle fibres [49]. 
a

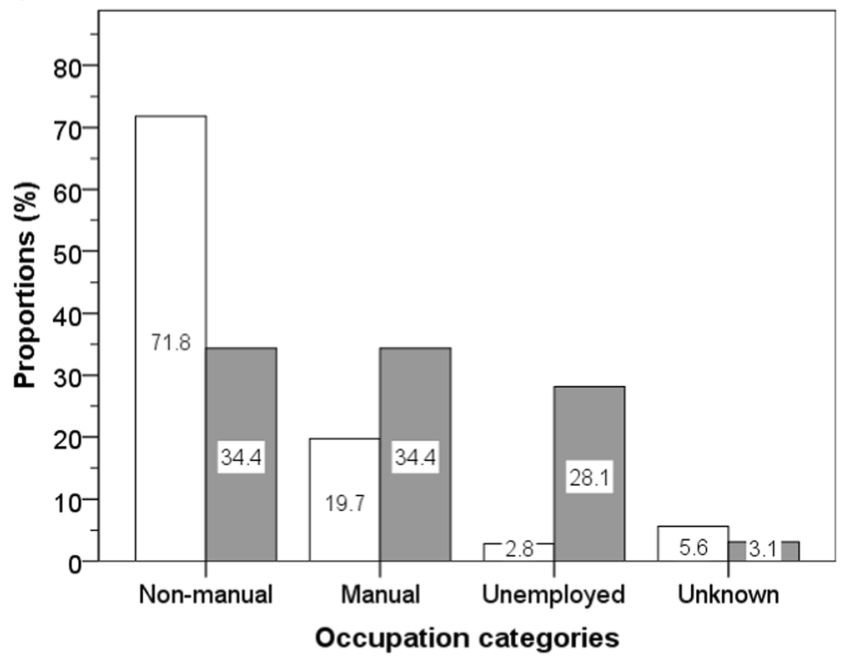

b

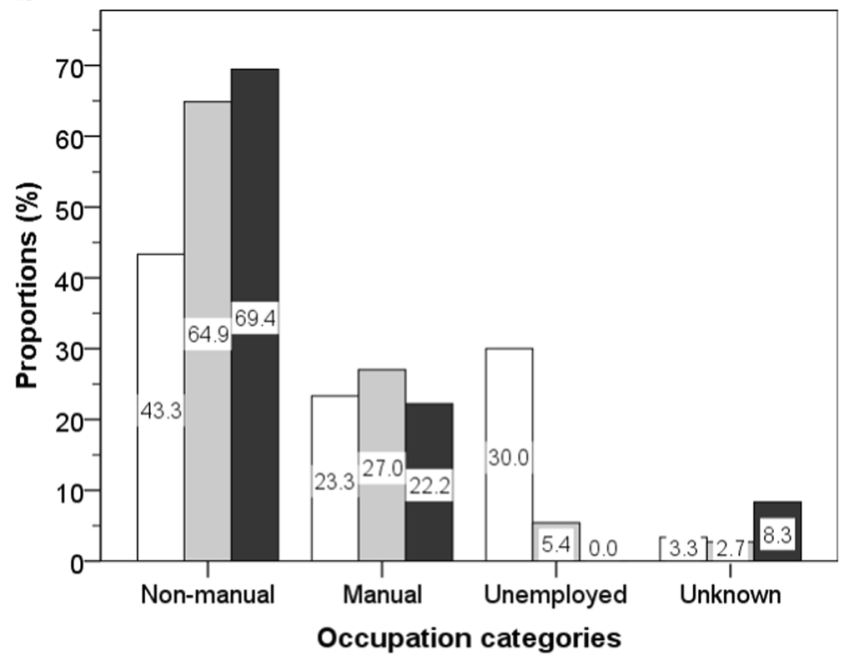

Fig. 3 Reported occupations after a boxing career in white boxers (white bars) and non-white boxers (grey bars) (a), groups differences: $\chi^{2}=20.6$, $p<0.001$ and in different tertiles of age of death: before 56.8 years (open bars), 56.8-74.5 years (grey bars), and after 74.5 years (back bars) (b), group differences: $\chi^{2}=18.9, p=0.004$

\section{Social Inequalities}

There may be differences in upbringing between whites and nonwhites, which would have influenced on their post-boxing environment. Generally, non-white boxers face greater risk of exposure to adverse environmental factors during their life time, away from boxing. A study on racial victimisation using the National Survey of Americans has revealed that up to a third of blacks had a history of arrest, $18 \%$ had been incarcerated, and their frequent exposure to traumas was associated with arrest and imprisonment [50]. We found substance abuse to occur across ethnic groups and occupations while convictions were higher among the nonwhite group. A number of studies have shown that people who suffer racism are at increased risk of stress-related mental health
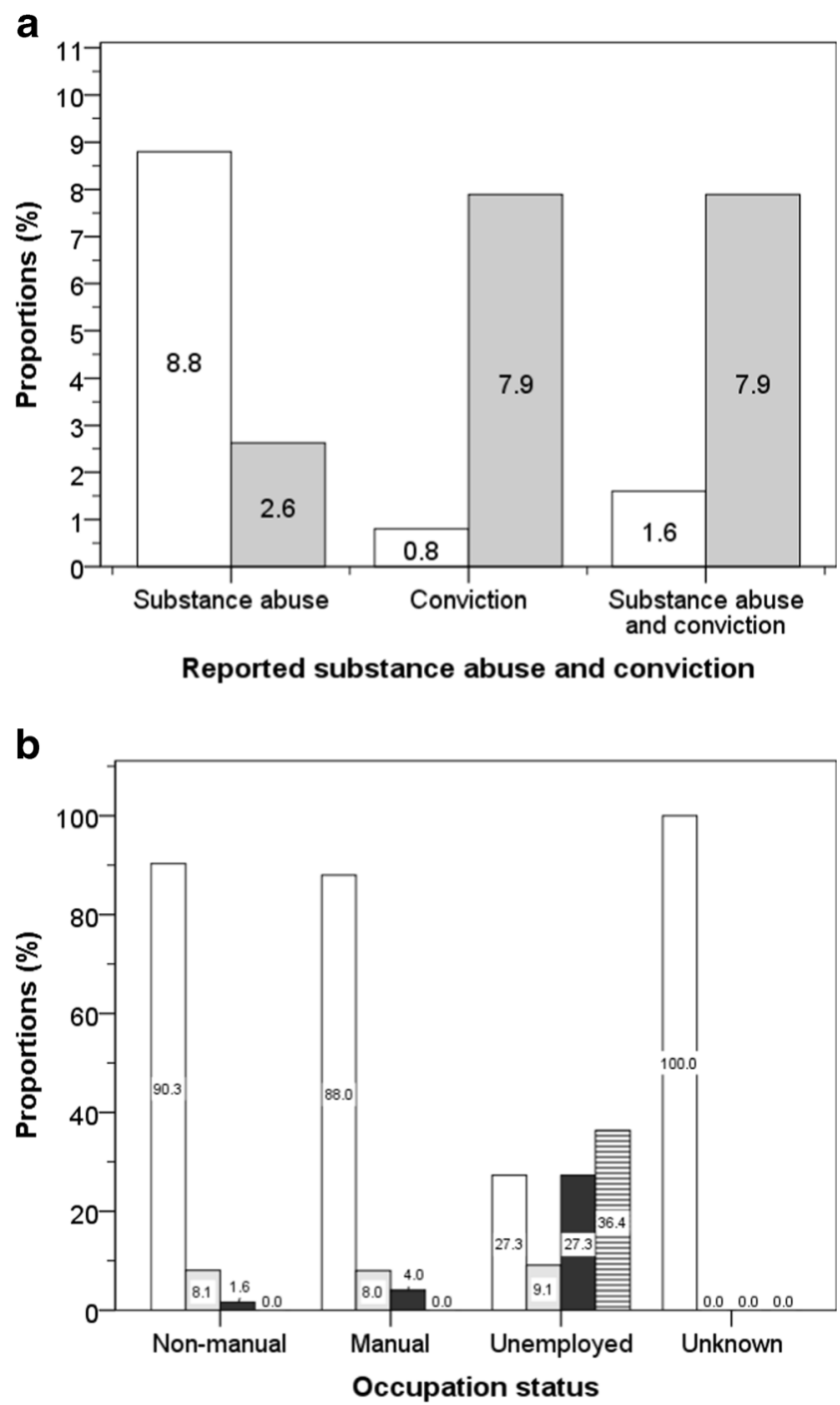

Fig. 4 Proportions of boxers reported in the media to have problems with substance abuse or convicted of crimes by ethnic groups (white bars $=$ white boxers and grey bars $=\mathrm{n}$ on-white boxers); group differences: $\chi^{2}=$ $10.5, p=0.005$ (a), and by occupation (white bars $=$ no reported substance abuse or conviction, grey bars $=$ substance abuse and black bars $=$ conviction of crimes; group difference: $\chi^{2}=40.1, p<0.001$ (b)

[22-24] and early death [25]. Williams et al. [23] showed a number of disadvantages among blacks compared with whites including lower education and income, larger household size, lower occupational level, and stress due to racism as well as general stress. These disparities are likely to extend to boxers.

\section{Post-Boxing Career Opportunities}

A boxing career at the highest level is short-lived. We found that on average, the time span during which boxers contested championship titles is 1.8 years, and their reign lasted for just 1 year (median). Half of the boxers' last contests for world titles were when they were less than 30 years of age; a third were between 30 and 35 years of age; and by the time they 
passed the age of 40 years, less than $4 \%$ were competing for a world title. It is likely that many of the boxers would continue to compete at a lower level (non-title bouts) but most would have retired from boxing before 40eayrs of age and needed to find a new career. World boxing championships are well known to provide the 'richest prizes in sport' since the first ever professional contest. In 1910, the purse for the winner was $\$ 151,000$ (equivalent to $\$ 4$ million today) [51]. The prize has increased progressively in real terms over the years, with the latest purse for a heavyweight title earned the champion $£ 20$ million (\$25.9 million) and challenger $£ 6$ million (\$7.8 million) [52]. As far as we are aware, there have been no report in differences in prize money awarded to white and non-white boxers, but there have been isolated reports including that of a white boxer who fought in the same contest, and lost, but benefited more than the black champion in secondary income such as copyright, e.g. film rights of the fight and sponsorship deals [51]. However, it is known that boxers often have their incomes badly managed [53] and it is possible that this may be more prevalent for non-white boxers. The Muhammad Ali Act in the USA was introduced in 1999 to protect the rights and welfare of boxers [54].

Retiring from boxing is often a sideways move into the training of young boxers (5.8\% of our study sample, among whom $50 \%$ were non-whites), and it is difficult to obtain reliable estimates of their incomes. A relatively high proportion of boxers (12.6\% of our study sample, among whom $69.2 \%$ were whites) invested in a sports club as owners or became elected officials in athletics. There was a significant discrepancy in post-boxing employment between white and non-white boxers. About three-quarters of white boxers acquired non-manual jobs, with under 3\% being unemployed. In contrast, just over a third of nonwhite boxers had non-manual jobs while almost $30 \%$ were unemployed or involved in illegal trades. Among the underlying reasons for this ethnic disparity, opportunities for higher education and training for new careers after boxing are likely to be important, as are social and environmental factors. We were not able to confirm the existence of support for further education and new career opportunities provided by national and international boxing organisations for boxers undergoing career transition. The lack of assistance for retired athletes is not restricted to boxing. Retired footballers have also demonstrated a rapid decline in physical and mental health $[55,56]$ with high rates of bankruptcy and divorce, as well as addictions and convictions [57]. Managerial jobs are almost exclusively occupied by whites in the English Premier League; currently, all black managers $(7 \%$ of all managers in the English Football Leagues) ply their trade in lower leagues. To address this imbalance, the Rooney Rule has been introduced which recommends that at least one black, Asian, and minority ethnic (BAME) candidate should be interviewed for every coaching role. This rule has been adopted by the Football Association but not yet by the Premier League, and only on a voluntary basis by the English Football League [58].

\section{Post-Boxing Occupations and Health Outcomes}

Our findings of the relationship between lower employment and increased risk of death are consistent with previous studies of the general population [59]. Boxing-related health consequences may play a part in the employment profiles and high rates of substance abuse and of criminal convictions among boxers. On the other hand, it is possible that lower employment status (manual occupation or unemployment) contributes to poorer health and earlier deaths in non-white boxers through poverty. Apart from the high risk of injuries related to manual work $[60,61]$ that may result in disability and death, it is plausible that low level of occupation, which is disproportionally higher in non-whites, leads to early death through poverty [59]; poverty is the fundamental cause of ill health through poor diet and lifestyle habits such as smoking, as well as poorer housing and neighbourhood environment [62].

\section{Strengths and Limitations}

Because of their celebrity status, these elite boxers are uniquely followed and reported on by the media, detailing their future achievements, their unwanted experiences and activities, and their deaths. Most of the boxers included here had published obituaries and biographies, and many have had continuous media coverage that contains a wealth of data, including career and life events as well as date of death. For many, there are publicly monitored resources such as Wikipedia. We also have complete anthropometric measurements for these boxers during their competitive careers, which are analysed in a separate paper [26]. Few other elite sports men and women have such demographic and anthropometric information documented by the media in the same way. There are some potential sources of error and bias, particularly in relation to the use of media reports for scientific analysis. There may be underreporting of bad publicity such as substance abuse and convictions. These may not be disclosed by the boxers themselves, and there is potential for ethnic bias in reporting these by the press if it is largely controlled by whites. Other factors such as smoking and physical inactivity after boxing may also have affected later health but that information was not available.

Despite achieving elite athlete status, non-white heavyweight boxers die at younger ages than white boxers with an excess of neurological and accidental causes of death. Non-whites had poorer social profiles in later life after their boxing careers with more substance abuse and criminal convictions. Sporting authorities should reappraise the 
wisdom of permitting blows to the head in sport and should monitor and support the health and wellbeing of sports people after retirement.

Authors' Contribution The original idea of this study was proposed by TSH and MEJL. TSH analysed the data and wrote the first draft of this paper. TSH, MEJL, PS, and JG edited subsequent drafts. All authors have read and approved the final version of the manuscript for submission.

\section{Compliance with Ethical Standards}

Competing Interests The authors declare that they have no conflicts of interest.

Ethical Approval This study was conducted in accordance with the 1964 Helsinki declaration and its later amendments or comparable ethical standards.

Statement of Human and Animal Rights This article does not contain any studies with animals performed by any of the authors.

Provenance and Peer Review Not commissioned; externally peer reviewed

Data Sharing Statement No additional data are available

Open Access This article is distributed under the terms of the Creative Commons Attribution 4.0 International License (http:// creativecommons.org/licenses/by/4.0/), which permits unrestricted use, distribution, and reproduction in any medium, provided you give appropriate credit to the original author(s) and the source, provide a link to the Creative Commons license, and indicate if changes were made.

\section{References}

1. Brown TH. Diverging fortunes: racial/ethnic inequality in wealth trajectories in middle and late life. Race Soc Probl. 2016;8:29-41.

2. Gaffney A, McCormick D. The Affordable Care Act: implications for health-care equity. Lancet. 2017;389:1442-52.

3. Nazroo JY. The structuring of ethnic inequalities in health: economic position, racial discrimination, and racism. Am J Public Health. 2003;93:277-84.

4. LaVeist TA. Disentangling race and socioeconomic status: a key to understanding health inequalities. J Urban Health. 2005;82:iii2634.

5. Marmot M, Friel S, Bell R, Houweling TA, Taylor S. Commission on Social Determinants of Health. Closing the gap in a generation: health equity through action on the social determinants of health. Lancet. 2008;372:1661-9.

6. Bor J, Cohen GH, Galea S. Population health in an era of rising income inequality: USA, 1980-2015. Lancet. 2017;389:1475-90.

7. Dickman SL, Himmelstein DU, Woolhandler S. Inequality and the health-care system in the USA. Lancet. 2017;389:1431-41.

8. Barata RB, Almeida MF, Montero CV, Silva ZP. Health inequalities based on ethnicity in individuals aged 15 to 64, Brazil, 1998. Cadernos de Saúde Pública. 2007;23:305-13.

9. Melo EC, de Oliveira EX, Chor D, Carvalho MS, Pinheiro RS. Inequalities in socioeconomic status and race and the odds of undergoing a mammogram in Brazil. Int J Equity Health. 2016;15: 144.
10. Laakso L. Social mobility of Finnish elite-athletes of different achievement level. Int Rev Sport Sociol. 1980;15:97-105.

11. Carrington B. Social mobility, ethnicity and sport. Br J Sociol Educ. 1986;7:3-18.

12. Knights S, Sherry E, Ruddock-Hudson M. Investigating elite endof-athletic-career transition: a systematic review. J Appl Sport Psychol. 2016;28:291-308.

13. Spaaij R, Farquharson K, Marjoribanks T. Sport and social inequalities. Sociol Compass. 2015;9:400-11.

14. Houlston DR. The occupational mobility of professional athletes. Int Rev Sport Sociol. 1982;17:15-28.

15. Schinke RJ, Stambulova NB, Trepanier D, Oghene O. Psychological support for the Canadian Olympic Boxing Team in meta-transitions through the National Team Program. Int J Sport Exerc Psychol. 2015;13:74-89.

16. Bonhomme, Justin. The career developments of two world champion boxers: interpretive thematic analysis of media stories. Diss. Laurentian University of Sudbury. 2018.

17. Gregg R. Personal calvaries: sports in Philadelphia's AfricanAmerican communities, 1920-60. Cult Sport Soc. 2003;6:88-115.

18. Rudman WJ. The sport mystique in Black culture. Sociol Sport J. 1986;3:305-19.

19. Wacquant LJ. The social logic of boxing in black Chicago: toward a sociology of pugilism. Sociol Sport J. 1992;9:221-54.

20. Floud R, Wachter K, Gregory A. Height, health and history: nutritional status in the United Kingdom, 1750-1980. Cambridge: Cambridge University Press; 1990.

21. Gems GR. Boxing: a concise history. Lanham: Rowman \& Littlefield; 2014.

22. Williams DR, Collins C. US socioeconomic and racial differences in health: patterns and explanations. Annu Rev Sociol. 1995;21: 349-86.

23. Williams DR, Yu Y, Jackson JS, Anderson NB. Racial differences in physical and mental health: socioeconomic status, stress and discrimination. J Health Psychol. 1997;2:335-51.

24. Schulz AJ, Gravlee CC, Williams DR, Israel BA, Mentz G, Rowe Z. Discrimination, symptoms of depression, and self-rated health among African American women in Detroit: results from a longitudinal analysis. Am J Public Health. 2006;96:1265-70.

25. Polednak AP. Segregation, discrimination and mortality in US Blacks. Ethn Dis. 1996;6:99-108.

26. Han TS, Callis TG, Sharma P, MEJ L. Secular trends in adiposity and musculoskeletal dimensions of elite heavyweight boxers between 1889 and 2019. Sport Sci Health. 2019 In press. https://doi. org/10.1007/s11332-019-00598-2.

27. Newspaper Archives, Obituaries \& Family History Records. https:// newspaperarchive.com. Accessed January 2018 to January 2019.

28. Newspapers. https://www.newspapers.com/. Accessed January 2018 to January 2019.

29. Fleischer N. Nat Fleischer's the Ring Record Book and Encyclopedia. New York: The Ring Bookshop, Inc.; 1977.

30. Mullen H, Mee B, Bozeat M. The ultimate encyclopedia of boxing. 9th ed. London: Carlton Books Ltd; 2018.

31. Wikipedia. Heavyweight boxing championship records and statistics. https://en.wikipedia.org/wiki/Heavyweight_boxing_ championship records and statistics. Accessed June 2018.

32. World Boxing Federation rules and regulations of championship contests. http://www.worldboxing federation.net/ wbfrulesandregulations.htm. Accessed June 2018.

33. Sandefur GD, Campbell ME, Eggerling-Boeck J. Racial and ethnic identification, official classifications, and health disparities. In: Anderson NB, Bulatao RA, Cohen B, editors. National Research Council, Committee on Population. Critical perspectives on racial and ethnic differences in health in late life. Washington: National Academies Press; 2004. 
34. Kochanek KD, Murphy SL, Xu J, Arias E. Deaths: Final Data for 2017. Natl Vital Stat Rep. 2019;68:1-77.

35. Morris M, Woods LM, Rachet B. A novel ecological methodology for constructing ethnic-majority life tables in the absence of individual ethnicity information. J Epidemiol Community Health. 2015;69:361-7.

36. Cunningham TJ, Croft JB, Liu Y, Lu H, Eke PI, Giles WH. Vital signs: racial disparities in age-specific mortality among blacks or African Americans-United States, 1999-2015. MMWR Morb Mortal Wkly Rep. 2017;66:444.

37. Gardner A, Iverson GL, McCrory P. Chronic traumatic encephalopathy in sport: a systematic review. Br J Sports Med. 2014;48:84-90.

38. Jordan BD, Relkin NR, Ravdin LD, Jacobs AR, Bennett A, Gandy S. Apolipoprotein $E \in 4$ associated with chronic traumatic brain injury in boxing. JAMA. 1997;278:136-40.

39. Corsellis JA, Bruton CJ, Freeman-Browne D. The aftermath of boxing. Psychol Med. 1973;3:270-303.

40. Corsellis JA. Boxing and the brain. BMJ. 1989;298:105-9.

41. Roberts GW, Allsop D, Bruton C. The occult aftermath of boxing. J Neurol Neurosurg Psychiatry. 1990;53:373-8.

42. Ling H, Hardy J, Zetterberg H. Neurological consequences of traumatic brain injuries in sports. Mol Cell Neurosci. 2015;66:114-22.

43. Kleindorfer D. Sociodemographic groups at risk: race/ethnicity. Stroke. 2009;40(3 Suppl 1):S75-8.

44. Bowman SM, Martin DP, Sharar SR, Zimmerman FJ. Racial disparities in outcomes of persons with moderate to severe traumatic brain injury. Med Care. 2007;45:686-90.

45. Bazarian JJ, Pope C, McClung J, Cheng YT, Flesher W. Ethnic and racial disparities in emergency department care for mild traumatic brain injury. Acad Emerg Med. 2003;10:1209-17.

46. Shafi S, de la Plata CM, Diaz-Arrastia R, Bransky A, Frankel H, Elliott AC, et al. Ethnic disparities exist in trauma care. J Trauma Acute Care Surg. 2007;63:1138-42.

47. Englum BR, Villegas C, Bolorunduro O, Haut ER, Cornwell EE III, Efron DT, et al. Racial, ethnic, and insurance status disparities in use of posthospitalization care after trauma. J Am Coll Surg. 2011;213:699-708.

48. Meagher AD, Beadles CA, Doorey J, Charles AG. Racial and ethnic disparities in discharge to rehabilitation following traumatic brain injury. J Neurosurg. 2015;122:595-601.

49. Lean ME, Han TS. Natural sporting ability and predisposition to cardiovascular disorders. QJM. 1998;91:641-6.

50. Jäggi LJ, Mezuk B, Watkins DC, Jackson JS. The relationship between trauma, arrest, and incarceration history among Black
Americans: findings from the National Survey of American Life. Soc Ment Health. 2016;6:187-206.

51. Waters J. The List: boxing's biggest money earners. Financial Times, 1 May 2015. https://www.ft.com/content/6ef03c34-f00e11e4-bb88-00144feab7de. Accessed June 2018.

52. Telegraph Sport. Anthony Joshua vs Alexander Povetkin prize money: how much of the fight purse will the winner get? The Telegraph, 22 September 2018. Accessed June 2018.

53. Baglio S. The Muhammed Ali Boxing Reform Act: the first jab at establishing credibility in professional boxing. Fordham L Rev. 1999;68:225795.

54. H.R. 1832 (106th): Muhammad Ali Boxing Reform Act. LIBRARY OF CONGRESS SUMMARY. govtrack.us. https:// www.govtrack.us/congress/bills/106/hr1832/text. Accessed 10/10/ 1019.

55. Gouttebarge V, Aoki H, Kerkhoffs GM. Prevalence and determinants of symptoms related to mental disorders in retired male professional footballers. J Sports Med Phys Fitness. 2016;56:648-54.

56. Gouttebarge V, Inklaar H, Frings-Dresen MH. Risk and consequences of osteoarthritis after a professional football career: a systematic review of the recent literature. J Sports Med Phys Fitness. 2014;54:494-504.

57. Gernon A. Retired: what happens to footballers when the game's up. Durrington: Pitch Publishing; 2016.

58. Hylton K. 'Race' and the Rooney Rule. Contexts. 2016;15.

59. Menchik PL. Economic status as a determinant of mortality among black and white older men: does poverty kill? Popul Stud. 1993;47: 427-36.

60. Rommel A, Varnaccia G, Lahmann N, Kottner J, Kroll LE. Occupational injuries in Germany: population-wide national survey data emphasize the importance of work-related factors. PLoS One. 2016;11:e0148798.

61. Takala J, Hämäläinen P, Nenonen NO, Takahashi K, Chimed-Ochir $\mathrm{O}$, Rantanen JO. Comparative analysis of the burden of injury and illness at work in selected countries and regions. Cent Eur J Occup Environ Med. 2017;23:6-31.

62. Marmot MG, Kogevinas M, Elston MA. Social/economic status and disease. Annu Rev Public Health. 1987;8:111-35.

Publisher's Note Springer Nature remains neutral with regard to jurisdictional claims in published maps and institutional affiliations. 